\title{
Exploiting Context-bound and Context-sensitive Aspects of Editorial Cartoons: Developing Linguistic and Critical Thinking Abilities in English Language Classrooms
}

\author{
Dr. Vijay Singh Thakur \\ Associate Professor, Department of Languages and Translation \\ Dhofar University, Salalah, Sultanate of Oman \\ Dr. Khalid Almashikhi, Ed. D \\ Acting Dean, College of Arts and Applied Sciences, Dhofar University, Salalah, Sultanate of Oman
}

\begin{abstract}
The use of humor and fun makes the class atmosphere more pleasant, motivates learners, increases studentteacher interaction, makes learning enjoyable and meaningful, and most of all, pleases the students. Editorial cartoons could be a rich source of all this and a lot more if used in an imaginative, creative and innovative manner for English Language Teaching (ELT).This paper, motivated by such pedagogical concerns, explores the idea of exploiting the neglected resource of context-bound and context-sensitive editorial cartoons and interactive approach to language teaching. It aims at demonstrating as to how it will work in developing students' language skills and critical thinking abilities and provide a stimulating learning experience in English Language Classrooms.
\end{abstract}

Keywords: editorial cartoons, critical thinking, interactive approach, context-bound, EIL classrooms

DOI: $10.7176 / \mathrm{JLLL} / 55-05$

Publication date: April $30^{\text {th }} 2019$

\section{Introduction}

It is significant to mark the way learning takes place. An American study (Thakur, 2004, p. 38) reports that we learn $1 \%$ by taste; $1.5 \%$ by touch; $3.5 \%$ by smell; $11 \%$ by hearing; and the maximum $83 \%$ by seeing. Thus, visuals seem to be playing a significant role in learning. Keeping this in mind, the visual teaching needs to be explored and exploited considerably.

By common consensus, pictures are the best visual aid. A Chinese maxim, highlighting this fact, says that one picture is better than a thousand words. Every picture tells a story and children are visual by nature. Put an editorial cartoon and a newspaper article in front of them- which one will they pick? Children gravitate more willingly toward cartoons. Why not take advantage of that natural attraction to cartoons in our classrooms then? The format of cartoons and caricatures is often richer in political, economic, and social impact. We can bring the power of cartoons, i.e. the strength of their images and the potency of their messages into the classrooms. Editorial cartoons cover a lot of high-level concepts of metaphor, simile, hyperbole, satire, irony, etc.; things that are harder to convey in text. Language isn't a barrier. It is all right there in the visuals. Thus, editorial cartoons can be a rich resource for a variety of purposes in language teaching.

\section{Why editorial classrooms?}

There are several qualities for which cartoons can be used for language teaching. They have a broad coverage on international affairs, population, pollution, love, adventure, war, corruption, nepotism, favoritism, scandals, personal and social life, etc., which enhances readers' general knowledge. They are easy to understand and the features of originality, freshness, unusualness, and spontaneity delight and refresh the readers. They provide realistic, truthful, authentic, and relevant information in a revealing manner. The information is presented indirectly and in a context. There may be, often, an opinion gap, i.e. the reader and the cartoonist may not agree on a certain issue, which renders a scope for the reader to put out his argument or opinion. Patil (1996) calls it the cartoonist's vantage point (p. 17). For these qualities cartoons can be recommended as suitable teaching material. But, they are not tailor-made as the cartoonist, perhaps, never draws them with the approaches and methods of ELT and the rules of word order and contextual meaning in mind. Hence, they need to be planned, prepared, and sometimes adapted for the purposes of language teaching.

The need to teach language in context and in an integrated interactive framework

Supposedly, as English language teachers we teach language skills to facilitate communication in the target language and it is a common knowledge that communication is always rooted in a variety of real contexts. Rivers' (2000) premise that 'communication' derives essentially from interaction' (p. xiii); Ellis' (2004) notion of 'natural developmental route to learning' (p. 63); and Long's (1996) argument that interaction and negotiation 
of meaning facilitate acquisition because they link input modification, internal learner capacities, and output in productive ways testify to the fact that language is learnt better through communication. Furthermore, Students achieve felicity in using a language when their attention is focused on conveying and receiving authentic messages, i.e. messages that contain information of interest to speaker and hearer in a situation of importance to both (Rivers, 2000, p. 4). Exchange, to use Wells' (1981) argument, is the basic unit of discourse, which implies centrality of interaction in language learning situations (p. 29). The arguments in these studies suggest that language teaching and learning activity should be context-bound, integrated, and interactive.

\section{How to use editorial cartoons in ESL/EFL classrooms}

Cartoons are very suitable for pair work and group work. They can be used for brainstorming and negotiation. While working in a pair or a group the students have to put their heads together to relate the cartoon to its social or political context and also they have to negotiate the meaning and message in the cartoon in consultation with each other. The exercise tends to become absorbing and involving while working on cartoons because the effort makes them think hard, and it also activates their shared knowledge and experience of the world. As Patil (1996) suggests, the students may be made to discuss the semantic, pragmatic, and sociolinguistic meanings of a cartoon and report their interpretations to the class (p. 17). Cartoons can also be used for written composition and interdisciplinary thinking. When a group works on a cartoon, they read it and also listen to others' opinions and ideas. When the group leader reports their interpretation to the class, he or she speaks and others listen. When groups write their composition on a cartoon, they make use of others' ideas gathered from the discussion. Thus, the use of cartoons promotes cooperative learning. The four skills of reading, speaking, listening, and writing can be integrated very easily with the help of cartoons and developed simultaneously as it happens in the natural course of language acquisition.

Editorial cartoons can be helpful in many other ways also. They can be used to develop and test students' ability to read between and even beyond the lines. Like literature, the cartoons make special uses of language. The captions in them are hypersemanticized, which could be used to enrich their language. They can be taught as to how a lot of meaning can be packed into a small presentation. Through cartoons we can teach our students the ways of saying the unsayable effectively. They can also be used to show how to be indirect in order to sensitize the students to the ways of being euphemistic. We can teach them how the meanings are context-bound and context-sensitive. We can also show them how a tragic event has a comic lining and vice-versa. By using the cartoons the past and present happenings, for example elections, may be taught. And, being value-loaded, we can use them for value education too.

Above all, the teaching through cartoons can enliven the classes, especially when they become monotonous and dull and the students then feel uninterested and bored in learning. Through cartoons they can have fun and relaxation. As Smith (1993) comments, there will be something in every cartoon to please even the most cynical student at the back of the class (p. 58).

The possibilities and scope for the use of cartoons and caricatures in teaching English are inexhaustible.

\section{Tasks that can be designed on editorial cartoons: Some examples}

A number of tasks can be set on cartoons. Let us explore some possibilities:

1. Here we have four cartoons that draw our attention to the phenomenon called polysemy. The meaning of a word depends on the context in which it is used. There is no such thing as the meaning of a word in isolation. And the success of communication depends upon relating the word to its right context. When a particular sense of the word in one situation is wrongly substituted for another situation then the problem of wrong contextual support arises and the communicative situation turns out to be funny and jocular. This is exactly what is happening in the following cartoons, i.e. Figures 1-4. 


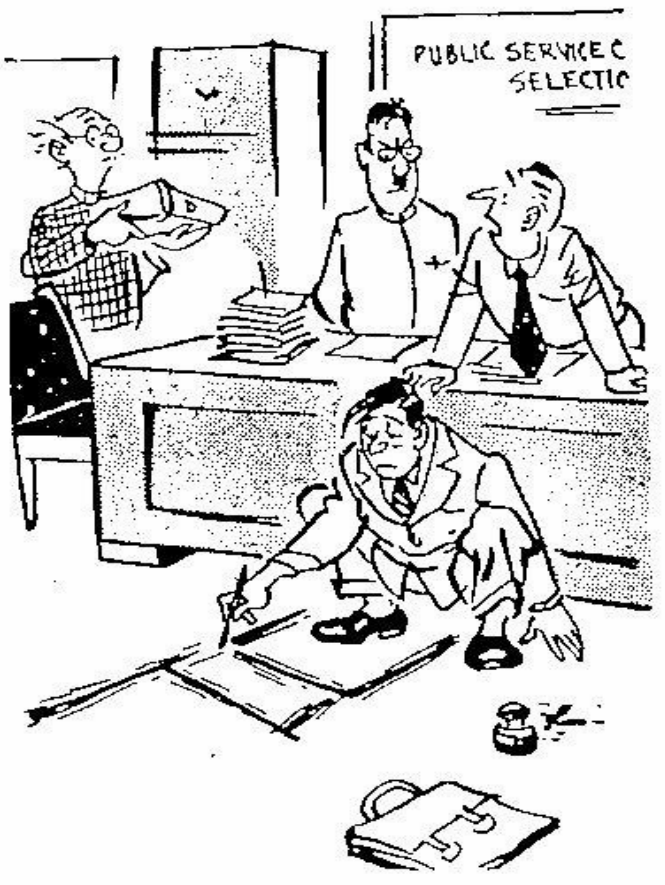

Ijust asked the candidate to draw a chair and sit down!
Fig. 1

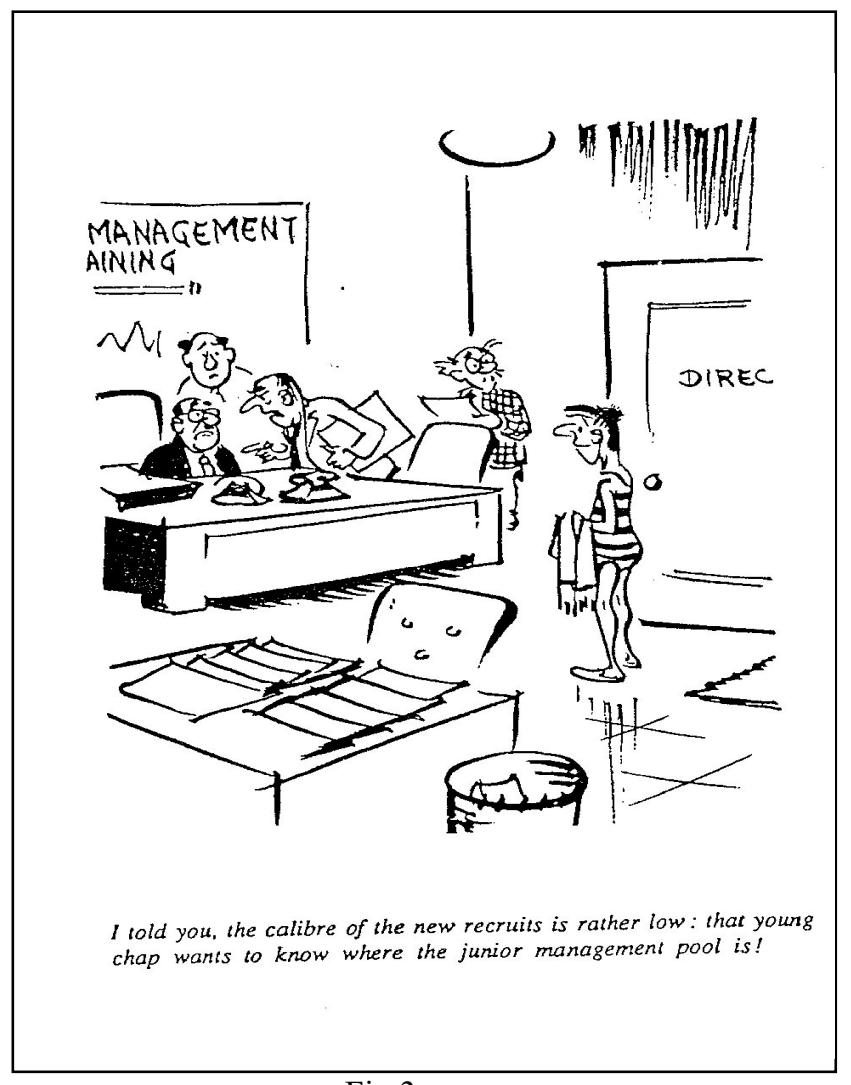

Fig.3

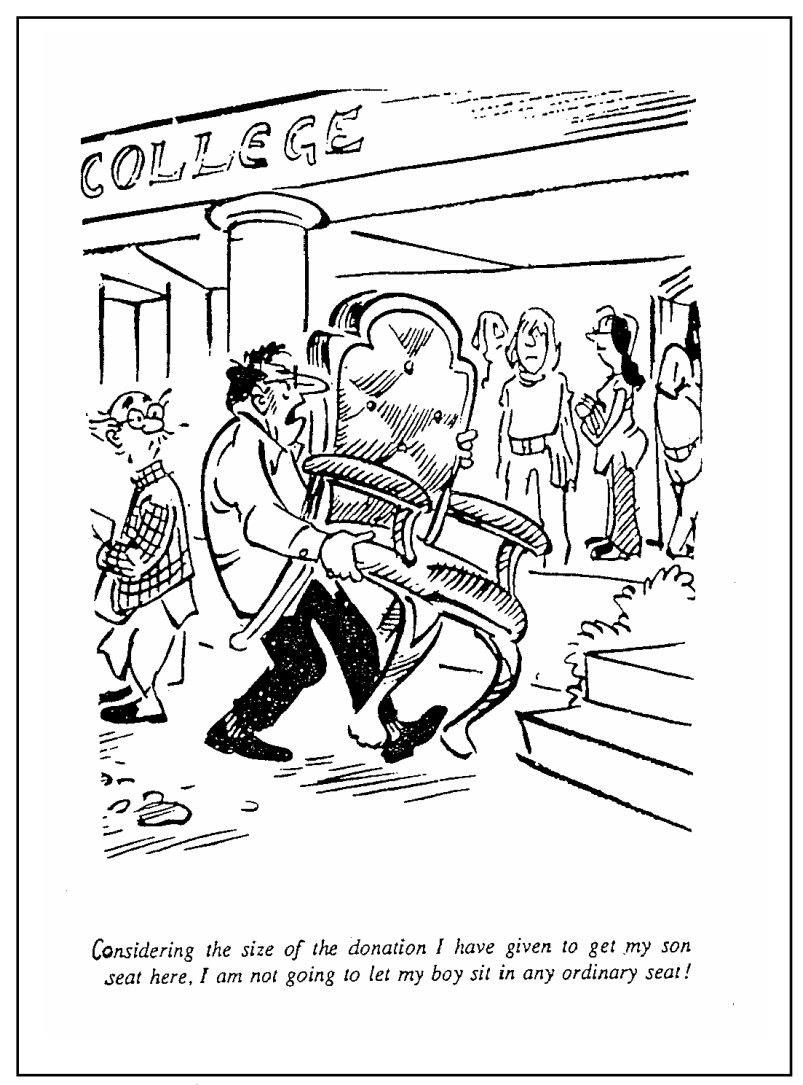

Fig 2

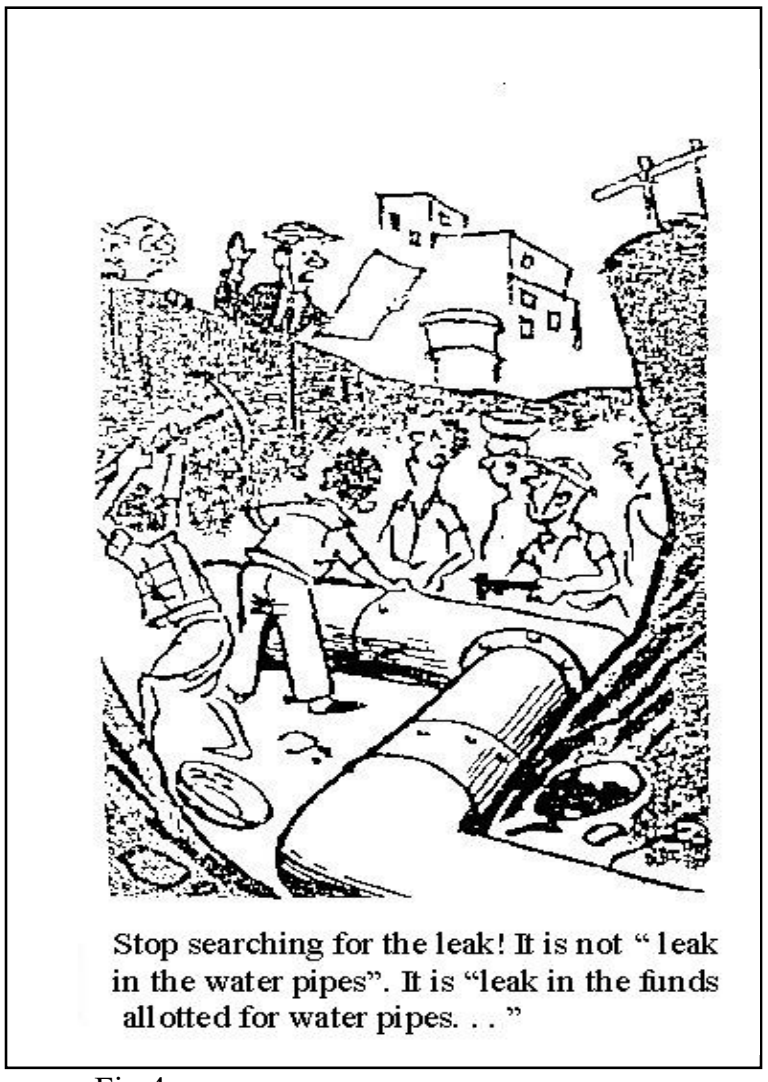

Fig.4

The main characters in these four cartoons have deviated from a specific context of use of the key words 'draw', 'seat', 'pool', and 'leak' and understood them in their wrong contexts. Meaning lies partly in words and 
the rest in the mind(s) of the speaker and hearer(s). In addition, context also plays an important role in determining the meaning.

Let us think of some activities that can be designed on such cartoons. The following are some of the possibilities:

(i) We can separate the pictorial content from the accompanying verbal content, jumble them, and ask the students to match them.

(ii) We can ask the students to replace the key words with the synonyms, for example 'pull' for 'draw, and 'place' for 'seat', 'group' for 'pool' and 'crack/hole' for 'leak' to explain how the effect and effectiveness of the cartoon(s) is lost.

(iii) Students can be asked to describe the situation in the cartoons and can be motivated to prepare parallel cartoons using different themes.

(iv) They can be asked to retell the story using their own words.

(v)We can ask our students to study the whole semantic range of the principal words and prepare word network for them.

(vi) They can be motivated to develop dialogic conversations between the participants in the cartoons, using the picture and the caption.

(vii) A guessing game can be planned. We can divide the class as per the number of cartoons. Each group will have one cartoon and will be required to supply clues, in instalments, to the other groups and they will have to guess the person(s) and the situation depicted in the cartoon. The target groups may be allowed to ask some choice questions to identify the person and the event portrayed in it. The game may go on till the groups succeed.

Only a few possibilities are suggested here. Several other things could also be done with such pictorial presentations. Let us examine some more cartoons, which are different in nature and theme and could be used for language teaching and evoking critical thinking.

2. Such cartoons, as the one in Fig. 5, can be utilized to make the students aware of connotation of words.

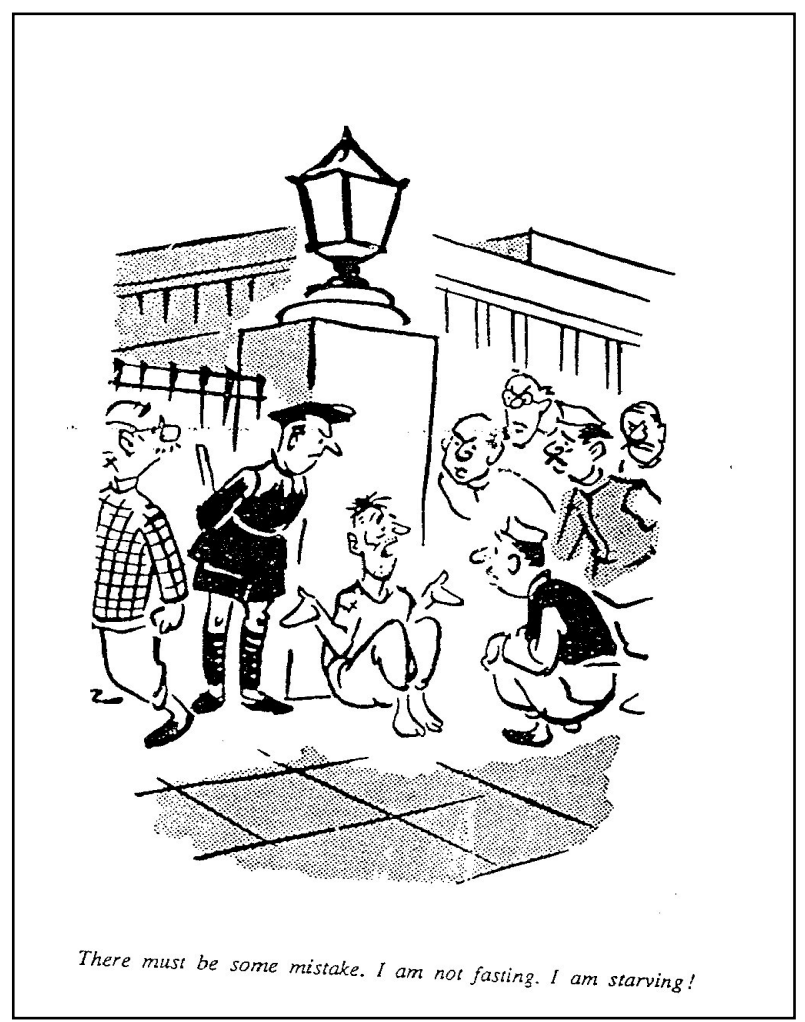

Fig. 5

In this cartoon the students may be asked to investigate the connotation of the two key words, 'fasting' and 'starving' which contrast with each other in the pictorial context of the cartoon and bring in satirical overtones in it. They may also be asked to find out as to which connotation the two words are latched on to. As an extension activity, the students may be asked to look for cartoons where such pairs of words are contrasted and to discriminate them on the basis of their connotation. For this they will have to scan a number of cartoons from the library and also have to refer to a dictionary for discriminating the words by their connotation. As a result, it will 
help develop their skills of reading for specific purposes. The students may also be asked to think of some synonyms like obstacle/hurdle, rare/scarce, considerate/thoughtful, careful/cautious etc. and discriminate them on the basis of their connotation as a brainstorming activity.

3. Let us look at another cartoon, Fig.6, which draws our attention towards the chameleon nature of words.

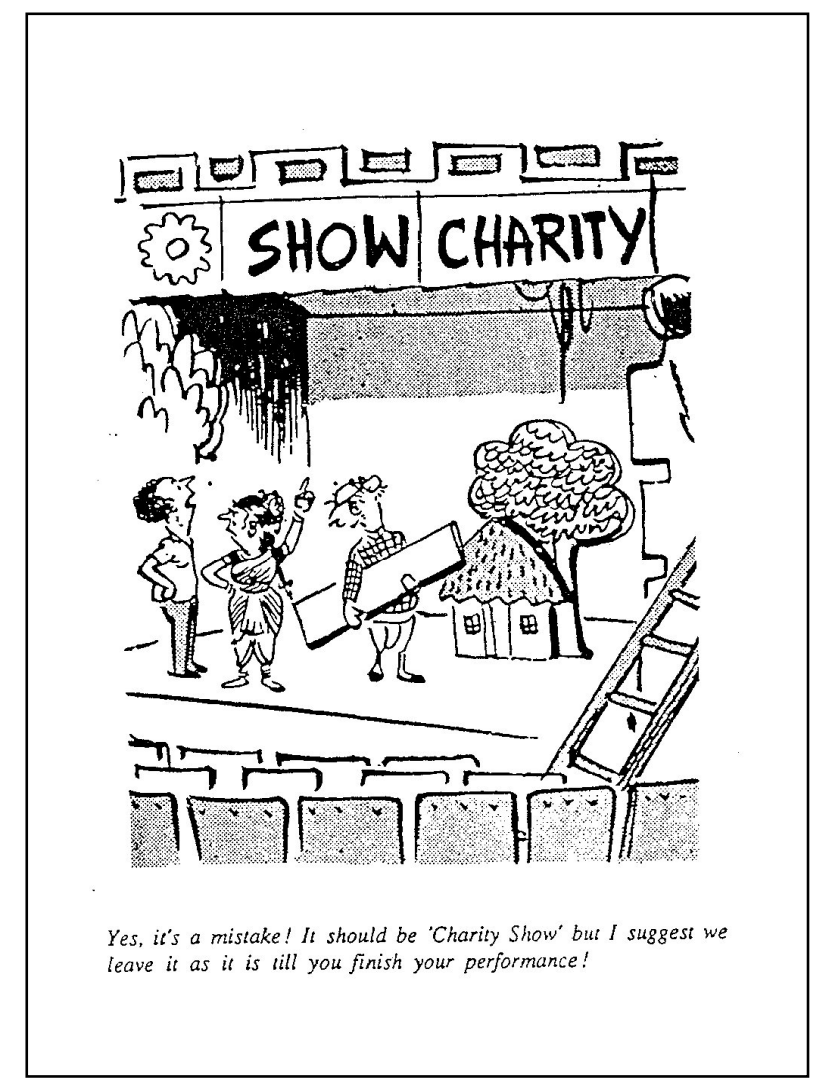

Fig. 6

As Patil (1996) suggests, this cartoon can be used to show how a phrase becomes a sentence, to illustrate how meanings depend on word order, and to explain how semantic meaning differs from pragmatic meaning ( $\mathrm{p}$. 19). The situation in the cartoon displays a lady dancer who has agreed to give her dance performance for charity purposes. The organizers of the show advertize it; but, instead of advertising it as 'Charity show', they advertize it as 'Show charity'. On the day of the performance the dancer looks at the banner, which makes her angry.

This cartoon can easily demonstrate the importance of sequencing. There is a contrast between the two sequences, i.e., 'Charity show' in the caption but 'Show charity' in the pictorial content. In the first sequence 'Charity' is an adjective and 'show' is a noun. But the same words in the other sequence obtain different grammatical form- 'charity' becomes a noun and 'Show', a verb. There is another difference. The first sequence is a phrase whereas the latter is a sentence. One more dissimilarity is there and that is the crucial one, which makes the performer angry. The sentence 'Show charity' has a derogatory meaning being an adverse comment on the dancer's performing abilities. It implies an appeal to the spectators to bear with her.

Students may be asked to uncover these differences and interpret the cartoon in their own language. They may also be asked to generate examples of similar contrastive sequences and discuss the difference in their structure and meaning. Some of the example sequences could be school day / day school, people concerned / concerned people, income tax / Tax income, process description / description process, Sentences involved / involved sentences, training workshop / workshop training, fast color / Color fast, literature study / Study literature, etc. 
4. The next two cartoons, under consideration, are very suitable for teaching reading between and also beyond the lines.

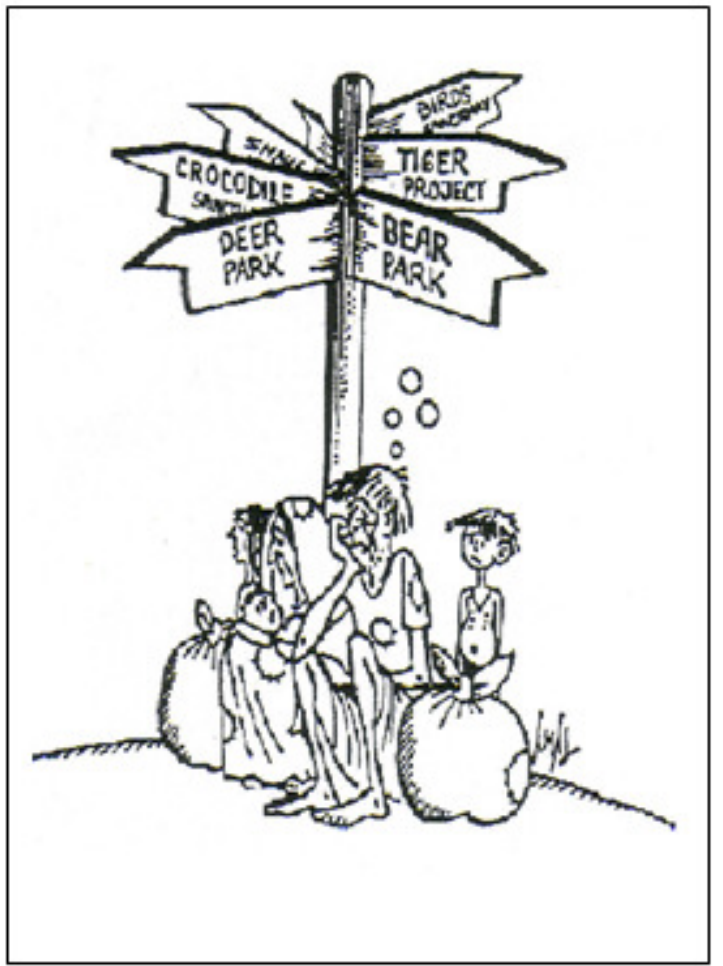

Fig.7

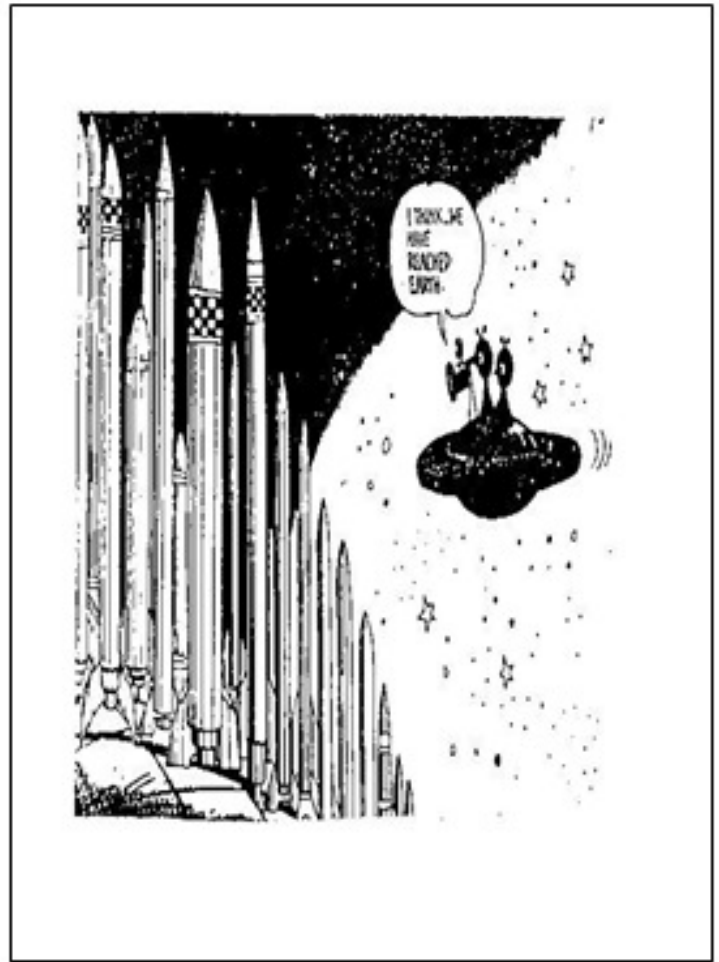

Fig. 8

The unexpected contrast present in the above cartoons can be used to activate the readers' sensitivity, awareness, and concern towards the issues brought up through them. Both the cartoons are packed with abundant meaning. The issues of 'poverty and homelessness' and 'arms race' have been raised by contrasting animals and human beings in Fig.7, in terms of their respective living conditions, and aliens from the other planet and human beings on earth in Fig.8, in the context of arms race. As the presentations are highly suggestive in nature, they offer a lot of scope for the readers to put their ideas and arguments out. We can use such cartoons for group work and ask the students to discuss and record their observations and reflections and write a detailed analysis. We can give them the following tasks: Analyze the cartoons. Your discussions should answer the following questions-(a) What is the central idea in the two cartoons? (b) Is the idea presented in an effective manner? (c) How can the same idea be presented differently, i.e. by using other situation? Discuss.

5. Among various other possibilities, the two caricatures in Fig. 9 and 10 can be used to summarize the ideas and thoughts that the two pictures display. 


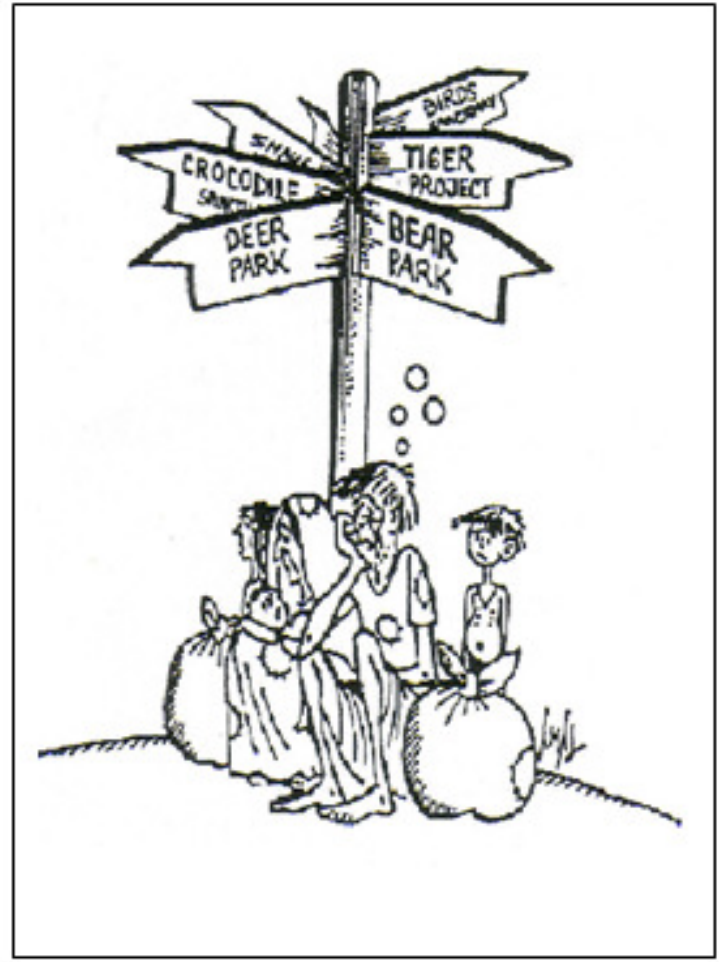

Fig. 9

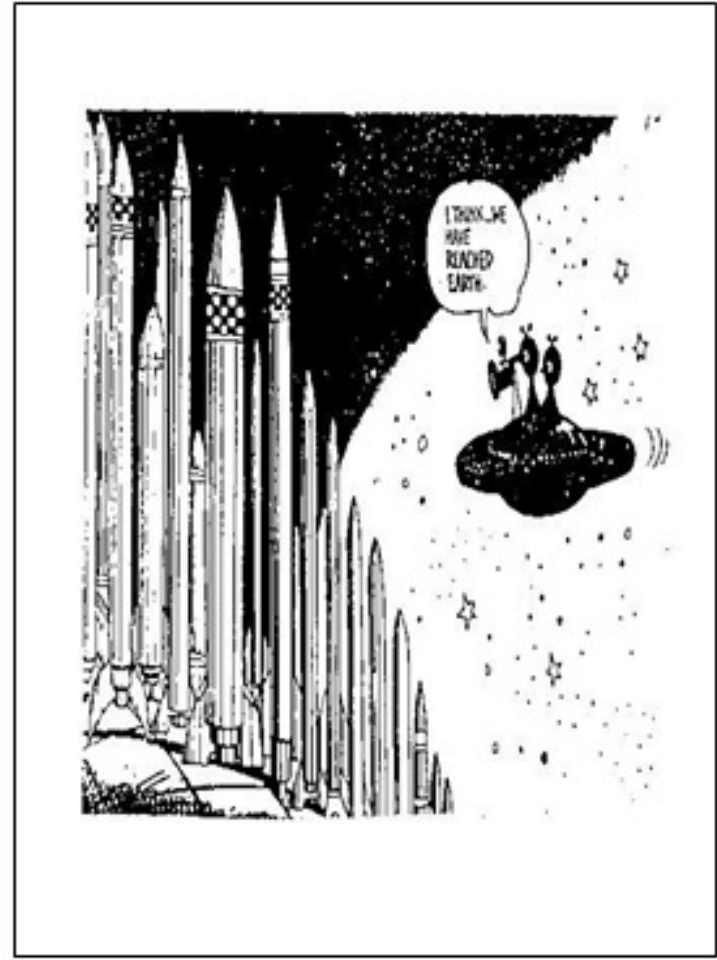

Fig. 10

Here the students can be asked to write a catchy title like 'Money to burn ...', 'Common man's burden ...' etc. They may also be asked to write small captions for the pictures. It is also possible to give them topics such as 'Smoking-- how good and bad?, 'Common man's life' and ask them to write small essays using the two pictures.

6. Let us examine another cartoon for a critical analysis of various aspects involved in it.

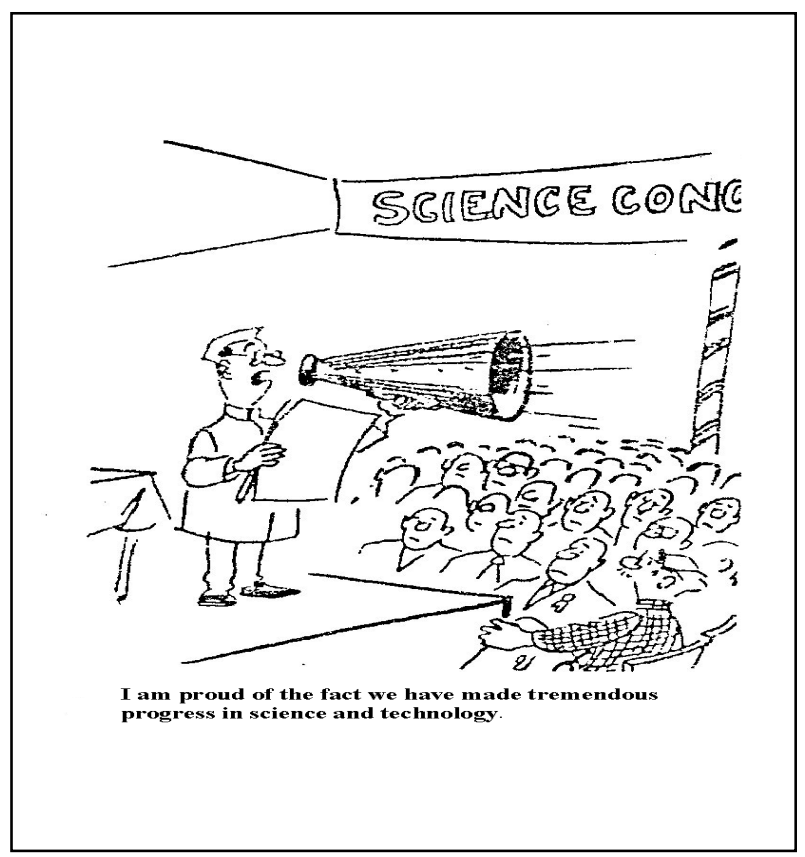

Fig. 11

This cartoon is on science in which a political leader is addressing a gathering of scientists and is talking about his being proud of the scientific and technological advancement of his country. The punchline of the satire lies in the obvious disparity between the verbal and pictorial aspects of the cartoon.

Here are some tasks (adapted from Patil, 1996, pp. 21-22) that could be set on this cartoon. 
(i) Study the cartoon and write down your observations.

(ii) Identify who is the speaker and who are hearers in the picture.

(iii) Complete the theme on the banner by using the word(s) that begin(s) with 'Con '. Do not use the word 'Congress'. Science Con

(iv) Explain the contradiction between the picture and its caption and discuss as to which part negates the speaker's statement and which heightens this effect.

(v) Do you think that the speaker and the hearers in the cartoon are aware of the irony of the situation? What makes you think so?

(vi) Suggest some changes in the picture and the caption, which can destroy the present effect of irony in the cartoon. (Some of the possible changes could be (a) A cordless or collar mike in place of a plain amplifier in the picture; (b) 'unhappy' in place of 'proud' and 'a little' in place of 'tremendous' in the caption)

(vii) Could you suggest some other captions for this cartoon? How effective would be the following- "We have miles to go before we sleep. And miles to go before we sleep" and "The wrong man in the right place." Discuss.

(vii) Imagine that you are a press reporter and you are asked to cover the function depicted in the cartoon. Write a small news report with a catchy title.

7. And finally, two more cartoons to reflect upon the cartoonist's vantage point:

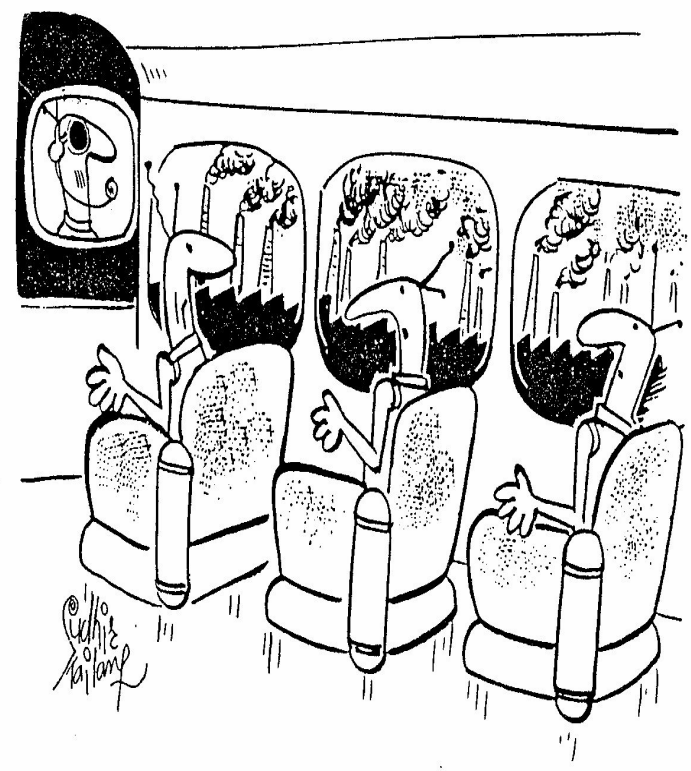

'This is your pilot speaking. We're about to land on earth. Please put on your oxygen masks!"

Fig.12

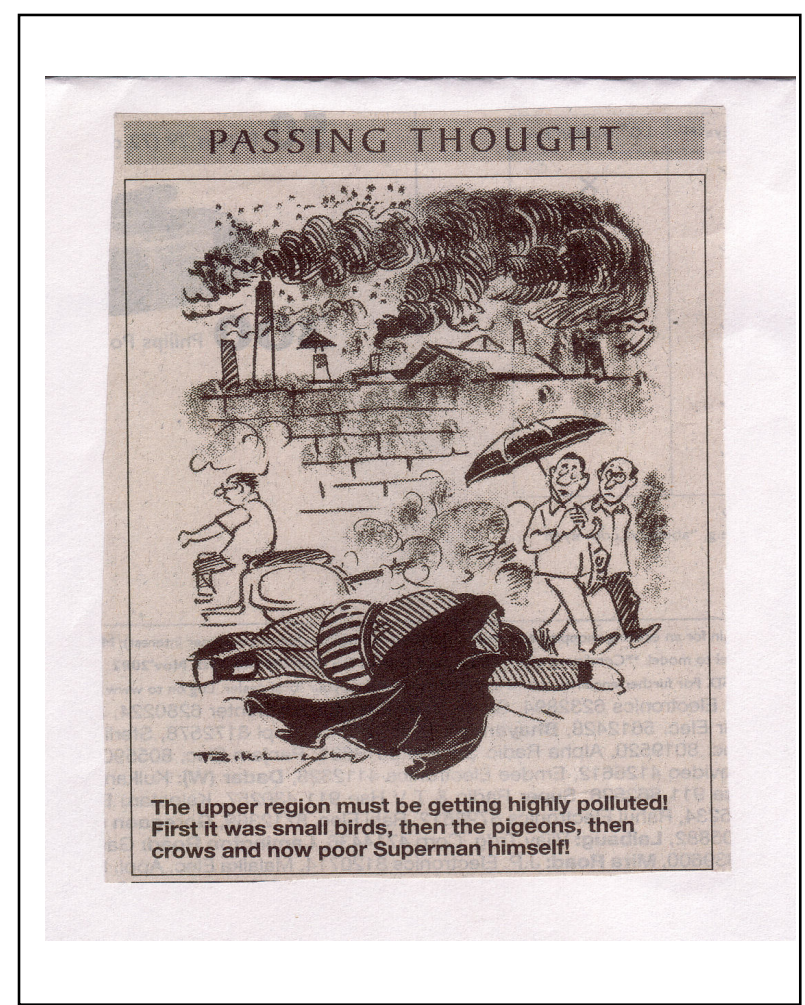

Fig. 13

Here, we can ask the students to work in groups, discuss, prepare opinions / arguments/ points of view and present to the rest of the class: (a) Study the vantage point adopted by the two cartoonists in their pictorial presentation. (b) Point out the humorous as well as serious aspects in the cartoons. (c) How much is true and how much exaggerated in the two pictures? (d) Is the exaggeration justified? Examine critically.

The list, of course, is not exhaustive. Many more other tasks and activities can be designed on these cartoons.

\section{Conclusion}

Editorial cartoons can be fruitfully used for a variety of purposes in language teaching. Our natural attraction towards visuals can be considerably exploited through the use of cartoons in English Language classrooms. With the help of carefully selected suitable cartoons every aspect of language can be taught and students' critical thinking abilities could be developed. Thus, good cartoonists have so much to offer for English language teaching and English language teachers and learners have so much to learn from them.

As cartoons and caricatures are an inexhaustible resource of humor and fun, the learner would enjoy working on them, and it will ensure better learner motivation and participation. An innovative and resourceful 
teacher can yield meaningful results in not only developing students' language skills but also promoting their higher order critical, lateral, and reflective thinking skills with the help of good cartoons. Hence, it is suggested and recommended that a judicious set of good cartoons, along with several learner-friendly tasks and activities, should be incorporated in the curriculum for language teaching.

\section{References}

Abraham, A. (1988). The Penguin book of Indian cartoons: Fig. 7, 8, 10, 12. New Delhi: Penguin Books.

Curry, D. (1982, rep.1994). Illustrated American Idioms: Fig. 9. Washington DC: The Materials Branch, English Language Programmes Division, United States Information Agency.

Ellis, R. (2004). Understanding second language acquisition. Oxford: Oxford University Press.

John,M. , et al. (1968). Building better English. New York, Evanston, London: Harper and Row Publications.

Long, M. H. (1996). The role of the linguistic environment in second language acquisition. In W. C. Ritchie \& T. K. Bhatia (Eds.) Handbook of research on language acquisition, 2 (pp. 413-468). San Diego, CA: Academic Press.

Laxman, R. K. (1967). You said it: Fig. 4, 11. Mumbai: IBH Publishing Company.

Lakshman, R. K. (1990, rep.1998). The best of Laxman: 1, 2, 3, 5, 6. New Delhi: Penguin Books.

Lakshman, R. K. (2002). Passing thought: Fig. 13. In The Times of India, 13 October.

Patil, Z. N. (1996). Using cartoons in the teaching of English. In B.T. Desai (ed.) JEFL (Journal of English and Foreign Languages), 17, 15-26.

Rivers, W. M. (2000). Interaction as the key to teaching language for communication. In Wilga M. Rivers. (Ed.) Interactive Language Teaching (pp. 3-16).Cambridge: Cambridge University Press.

Smith, J. (1993). Cartoons in the class. Practical English Teaching, June, 58-59.

Thakur, V. S. (2004). Teaching English through cartoons and caricatures: A viable approach. In V. V. Vincent (ed.) Muscat Message, April, Sultanate of Oman: Ministry of Education.

Thakur, V. S. (2005). Using supplementary materials for the teaching of English. In V. V. Vincent (ed.) Muscat Message, Sultanate of Oman: Ministry of Education.

Wells, G., et al. (1981). Learning through interaction: The study of language development. Cambridge: Cambridge University Press. 